\title{
On the Development of Higher Education Training Model and the Innovation of Quality Education for Probability and Statistics Curriculum
}

\author{
Xiao Xiaonan \\ Xiamen University Tan Kah Kee College \\ Zhangzhou, Fujian, China \\ E-mail:xiaoxn@xujc.com
}

\begin{abstract}
With the rapid development of modern science and technology, college graduates with comprehensive abilities are in great demand. Training their students to meet the need of this information era is a glorious and urgent task for high educational institutions. Tracking the development of modern technologies, developing new teaching methods, reinforcing the curriculums, unlocking students' potential of creativity, connecting colleges with the international community are the directions we need to go, in order to produce enough competitive talents to meet the demand of the 21 st century world.
\end{abstract}

Keywords—probability and statistics; innovation of quality education; the Information Age; creative talents.

\section{INTRODUCTION}

In today's information society with highly developed science and technology, the ability to cultivate a large number of high-quality creative talents with the mastery of advanced ideas and modern technology is an important factor to determine the overall strength of the nation. With the development of modern science technology, higher requirements were put forward on the creativity of college students. In this regard, the teaching of probability and statistics courses which serve as the foundational courses in the colleages of science, engineering and how it should meet the needs of the development of contemporary education economy in an effort to train students into the high-quality personnels with comprehensive innovation ability have become a pressing task we are facing now[1]. Years of teaching and research practice make me realize that to achieve this goal, we should not just confine ourselves to the existing books to impart knowledge of mathematics, more importantly, we need to combine the development of modern science technology, constantly update course content, improve teaching method, and integrate the research activities into the teaching process. It is crucial to pay attention not only to students 'mastery of modern scientific knowledge, but also to the cultivation of students' scientific research ability. It is only through this way that we can truly foster the students into high-quality personnels [2].

\section{UNDERSTANDING THE SIGNIFICANCE OF THE}

CULTIVATION OF APPLIED, COMPOUND AND INNOVATIVE TALENTS MAJORED IN INFORMATION AND COMPUTING SCIENCE

The 21st century is an information era based on the information technology and computer science technology, in order to better adapt to the new century's requirement of the cultivation of applied, compound and innovative talents in private college and the need of contemporary development of knowledge-economy, it has become an urgent task to deepen teaching reform, accelerate the establishment of a new type of private college undergraduate talents training mode. And for the regulation on the cultivation of talents in the major of information and computing science of private college, we think, it is generally needed to experience three dynamic development stages from the applied mode, compound applied mode to high-quality compound applied mode, so we should constantly adjust the talent training scheme.

After five years' school-running practice, our school has grown greatly; the teaching quality has greatly been improved. Today, in order to transfer from the stage of cultivating application-oriented talents to the stage of cultivating highquality composite applied innovative talents as soon as possible, we should not only further accelerate the changes of running condition of talent training pattern, including innovative culture, innovative teaching team, innovative teaching base as well as innovative talent training education, but also pay great attention to high-quality compound application-oriented student knowledge structure design and cultivation[3]. Applied innovative talents in information and computing science specialty should not only have the basic + frontier and multidisciplinary knowledge structure, but also have prominent critical thinking and practice ability, application and creative ability[4-5] .

To sum up, the talents training target and positioning in the major of information and computing science is training compound applied innovative talents, namely training outstanding high-quality composite applied talents with comprehensive practice ability, good innovation ability [6]. The features of talents' cultivation plan are:

Laying a theoretical foundation, cultivating comprehensive thinking ability, strengthening practice teaching, strengthening 
practice application ability, integrating multi-disciplinary knowledge, fostering innovation practice ability, creating innovative culture, stimulating creative and practical ability, offering innovative courses, cultivating the innovative application ability[7].

\section{LAYING A FOUNDATION, STRENGTHENING APPLICATION, AND ENHANCING THE STUDENTS' COMPREHENSIVE QUALITY AND INNOVATIVE APPLICATION ABILITY}

Scientific orientating, based on combining knowledge of multiple subjects, including mathematics and computing science and information science, improving the training of information technology, computing science technology and computer application skills to train application-oriented, versatile and innovative talents in the disciplinary field that combines information technology and computing science technology to meet the needs of the country

Based on the objective and orientation of talent-cultivation in the major of Information, Computing Science in our college, combining the conditions and advantages of our college and the requirements of employing units and society, the dominant thought of education program on Information, Computing Science Major in our college has been established, that is making students of lay a solid foundation of knowledge and expertise of the wide training and learning through four years' learning, enabling them to apply mathematic method and scientific computing skills and computer technology to solve information science, science and engineering computing and the practical problems of economic management, nurturing students to become engaged in scientific and engineering computing, computer application and software development, information systems designing, analysis and management with a strong dedication, innovative spirit of the compound, applied creative talents through strengthening information and computing science's basic theory, methods, and computer skills training and comprehensive training, as it is based on developing students moral, intellectual, physical and aesthetic development and forming a good mathematics and mathematical thinking.

Constructing curriculum of multi-disciplinary knowledge system of integration with a pattern of basic + knowledge frontier, improving abilities and quality structure of the compound, applied knowledge, creative talents.

The implementation of the three education modules, namely, skills education module, general education module, professional education module, ensures the systematic knowledge, but also highlights comprehensive integration of multi-disciplinary knowledge. Based on a solid theoretical foundation, the overall program stresses the highlights of the professional practice, innovation and comprehensive application of quality. Compared with Fudan University, Xiamen University, and Jimei University, the program significantly strengthens the information and computer science theory, methods, and computer skills training and practical application of the comprehensive training to provide a strong support in improving training compound and application talents.
Strengthening comprehensive education, strengthening the fusion and penetration of knowledge

According to the educational objectives and orientation in the major of information and computing science in our college, we strengthen the importance of the practice teaching, the comprehensive education and training for students in the curriculum design, and organically merging the courses with each other, so that we make a optimized performance of the course contents, further develop the students' ability of coming theory with practice and the ability to analyze and solve questions, thus effectively arousing the students' exploration and innovation spirit .

For example, in the revision of the professional education, we aim at the teaching practice of "operations research foundation" and "optimization method" knowledge module. We will combine the basic theory of operations research and optimization method with practice teaching, and a new course "strategy and optimization" is fused as a whole by means of the common case teaching. A new course named "information and coding" by combining information theory foundation with coding theory is created according to the practical teaching of " introduction of information theory" and "coding theory" knowledge module. Thus we further optimize the teaching plan, improve the teaching quality and reduce the credits and class hours and strengthen the comprehensive training.

Vigorously promoting the new educational model teaching in the classroom is the key to develop students' innovative spirit and ability

With the requirements of creative education, we pay particular attention to putting the subjective initiatives of the students into full play by breaking the old ways of thinking; following aspects of the conceptual changes have been made:

Firstly, the transformation from uniformity to diversity must be made. To inspire the students in daily instruction, we must break the traditional teaching method "try to do everything for the students" and "speaking from the beginning to the end", reading, discussing, speaking, training must be in combined in the implementation, a democratic equal relationship between teacher and students must be established to create a harmonious teaching atmosphere, respect students' thought, differences, creativity, and allow student to see the importance of active exploration, detailed thinking, and putting forward to some creative views, thus putting the students potentials to the top of their abilities.

Secondly, the transformation from closed to open teaching is realized. Open teaching is to replace the traditional closed case. Inspiring teaching will encourage teachers to think in advance, leading to the thinking shift from habitual ways of thinking to creative thinking. Thus, teachers must first of all combine knowledge on their own so that they could inspire and guide students in the classroom. In the teaching process, we also pay special attention to guiding student to make a meaningful outlook, exploiting the students' potential so that they can closely link to future employment, career design, and entrepreneurship in the right way.

Thirdly, transformation from static to dynamic teaching is made. In the classroom, "dynamic" method is opposed to the 
"static" concept, which refers to teachers, students, environment, resources are constantly changing, and many factors are interrelated, interacting to form a more complex and more changeable "Field" process. In classroom instruction, the dynamic process requires teachers to improve teaching knowledge and recognize students' abilities. Thus teachers can have a more comprehensive, deeper understanding of the strengths and weaknesses of students, guide students according to the characteristics, thereby effectively improving teaching effectiveness.

Fourthly, updating teaching content is to be made at any time. With the rapid development of modern knowledgeeconomy with a variety of new knowledge and new skills emerging, the employers require the knowledge of university talents training, skills and qualities to be further improved, which requires teachers to continuously adapt to social development requirements, make timely adjustments and updating to go step by step with the market., constantly updating teaching content by reflecting recent advances in the discipline, thus a basic organic innovative fusion is to be fully realized. Truly training our students to be high-quality composite and innovative talents to meet the requirement of social development

Fifthly, fully arousing the students' active participation must be made. Teaching and learning are the two aspects in the course of study. To improve the teaching, teachers play a better leading role; students must have the initiative and co-ordination to make. Fostering innovative spirit of the students need positive guidance of teachers, which in essence is to train the concept and awareness of respecting innovation, pursuing innovation and being proud of innovation. In teaching, we often use both classroom lectures and class discussions to solve the contradiction of course content, educating students to be insatiable for knowledge. And the ability to discover problem, raise questions and solve problem, popularizing the instructional mode to promote autonomous learning of students under the guidance of the teachers. Practice shows that the interaction and discussion in the classroom can supervise students, make them develop a comparative systematical learning pattern, through which students can obtain a sense of fulfillment, therefore mobilizing and motivating the students' interests in course and willing to study, educating and motivating students' in innovation[8-11]

\section{THE COMBINATION OF TEACHING AND RESEARCH, SUBLIMATION OF KNOWLEDGE, IMPROVEMENT OF QUALITY, AND PROMOTION OF REFORMS}

Teaching process is in the course of a constant imparting and updating of knowledge. A long-term teaching practice in colleges gives us a deep understanding that teaching and academic level can directly affect the teaching quality, while high-level talents can only be fostered by high-level teachers. Therefore, in the teaching of probability and statistics, we are fully prepared not only by delving into the materials but also pay attention to the increasing use of research activities combined with the teaching to deepen the understanding of knowledge, to control the development of the subject to obtain the latest knowledge. Thus, we can on the one hand improve the teaching and academic level and on the other hand enrich and update the course content from a new height with the latest development of the subject into teaching so as to open the students' horizons and broaden their knowledge. Moreover, it is helpful for students to have a better understanding of the course, which unconsciously plays an important role in building their creative thinking and pioneering spirit.

To further promote the comprehensive development of the quality of students, we pay special attention to strengthen the cultivation of students' ability to think independently, to act practically and to think creatively. Based on the above, teaching methods with the combination of heuristic, discussion and guidance against the basic concepts confusion, fundamental theories indigestion, and some pitfalls during the problem-solving help students learn to summarize methods to find the answers by themselves, which effectively cultivate students' creative thinking skills and abilities to deal with the practical problems with probabilistic methods.

To deeply explore the methods of the ground-breaking teaching models and approaches comprehensively, aiming at conquering the pure imparting of knowledge, we should not only emphasize the solid foundation of knowledge, but also a deep exploration and updating of the textbook by renewing the forefront contents related to the subject, integrating the relevant scientific achievements into teaching and broadening the horizon and thinking of students based on but higher than the textbook itself [12]. As in the teaching of "hypothesis testing", which is difficult for students to understand given that there is no explanation to the connection between hypothesis testing and interval estimation in current textbooks, professors can give the students some ideas based on their existing research in the teaching process, which naturally extend the confidence intervals to the ways of hypothesis testing resolution. In this way, students can have a deep understanding of the problem itself and get aroused with their interest in learning by realizing the dialectics in mathematics.

Furthermore, in order to enable students to make better use of probabilistic methods to solve practical problems and to lay a solid foundation for further learning, we have to insist on a "grasp the basis, highlight the key points, attack difficulties, and implement practically" teaching method. According to the characteristics of probability and statistics, for instance, abstract concepts, flexible approaches, complex and changeable exercises and difficulties in learning etc., we should at the same time penetrate the basic concepts and focus on some representative examples and some mixed-up problems to do some in-depth analysis, leading students to be open-minded and figure the ways out. More than that, we have done a deeper analysis of the "hard" and "easy" in mathematical statistics to make it easier to be taken in by the students. To briefly explain the "hardness", this can be attributed to the restrictions of credit hours and the foundation of the knowledge; while "easiness" can be ascribed to the teaching method and distinct explanation of the problems. In fact, we can draw a conclusion by following the required procedures on account of the fixed formula and method. To be specific, "hardness" can be mainly reflected in the deriving of normal distribution, $x^{2}$ distribution, $t$ distribution and $F$ distribution; to the contrary, "easiness" is the theory we have proved beyond the above ones, which merely cite the relevant conclusions and relative calculation of the 
above distributions (mainly by referring to the table look-up), which is not that difficult. Therefore, we should pay special attention to conversion work between "hardness" to "easiness" in teaching, focusing on clarifying the relevant table look-up of the four distributions mentioned above. By explaining the common mathematical statistics after students being familiar with the four distributions and table look-up, it will be much easier to acquire the knowledge.

Practices show that the combination of teaching methods and research is beneficial to develop creative thinking and cultivate the comprehensive quality of the students, which is popular among students and has played an important role in improving the teaching quality. In this regard, we will make contributions to improve the teaching quality of basic courses, deepen teaching reforms and strengthen the competenceoriented education with efforts.

\section{In-DePth Guidance, Pragmatic InNovation, PRACTICE STRENGTHENING AND ABILITY TRAINING}

With the advent of knowledge economy and information era, innovation consciousness and ability have already become the driving force to promote the development of science and technology. New Century requires college students not only have a solid foundation of knowledge and expertise, but also requires students to have the practical ability, innovation and comprehensive thinking capacity, etc[13]. to solve problems independently. To develop students' ability to innovate, professors primarily need to update their ideas on and on and develop their own creative thinking and innovation. To this end, teachers should continually keep space with the situation of science and technology development, focus on the development of the subject and continue to collect new materials to enrich and the teaching content, making it more interesting to learn.

Knowledge renewal derives from learning and innovation, which is not a separate capability, but an integration of thinking, imagination, analysis and observation. We should hereby pay more attention to cultivate the initiative, enthusiasm and creativity of the students to avoid them being regarded as passive recipients of knowledge, we should treat them as the main subject who can learn with motivation in education activities. Therefore, we should focus on application teaching by more practice and guidance, which leaves students some leeway to think and research independently in order to further develop the students' initiative in teaching activities. A famous scientist Yang Zhenning ever said that study should not be the final goal of learning, while it should be a tool for digging out new knowledge and new systems, which should indeed arouse our attention. According to the learning characteristics of probability and statistics, we should pay special attention to inspire our students to classify, to summarize, to generalize and to apply with flexibility and solve problems practically in a dialectic and multi-perspective way on the typical theory systems and thinking methods. We should also encourage students with enthusiasm to actively participate in extracurricular science and technology activities by doing some affordable research. In recent years, we help our students with launching research activities and guide quite a few students with their papers in topic-selecting, material-collecting, topic- confirming, general-conceiving, outline-compiling, structurestandardizing and final-version modifying, among which some get published in the national public academic journals, which has played a positive role in accelerating students' motivation in learning mathematics. Students through participation in research activities can not only enrich the knowledge, broaden the horizons, expand the mind, but also cultivate the ability to innovate. For both teachers and students, this is certainly an innovation in teaching methodology.

\section{To Update MODELS AND TRANSCEND TRADITIONS, TO SEEK ENDLESSLY AND BREAK COURAGEOUSLY}

With the rapid development of modern science and technology, the speed of updating knowledge is accelerating. In this regard, the teaching of colleges and universities should seize the opportunity to enhance quality education of students, and create more complex, innovative high-quality talent for country[14]. These have become an important subject urgently needs to explore by all the teachers in the teaching practices of colleges and universities. According to characteristics of higher learning educational teaching and personnel training requirements, we have to use the modern education teaching methods to explore the teaching rules, enhance teaching methods and improve teaching qualities. To face of problems of teaching reform for mathematical teachings in public basic course, we should break through the traditional teaching mode, learn new knowledge in the teaching, and deeply study the international and domestic first-class mathematics, combine with the development of modern science and technology, and constantly update the teaching contents. By use of heuristic methods, open type, artistic research teaching, we should strengthen the combination of teaching and scientific research, and make scientific research activities integrate into the whole process of teaching and education. We would innovate the traditional single teaching type teaching mode to turn boring cramming system into academic discussion. And also, the teachers and students should be expanded into a large modern international teaching and research platform. What's more, we have responsibility for cultivating students' creative ability and analytical problem-solving skills to students become pillars of the motherland and lay solid foundations in the future.

Creating outstanding university and training first-class talents, these are not only a great glorious and arduous task given by information age, but also an urgent call to higher education in China from the 21 st century. This is our teachingdirection in the future .In front of the glorious and arduous task, we must have the courage to explore, practice and break through, accelerate changing education idea, and deepen teaching reform. We also need cultivate more excellent talents for the rapid development of higher education.

\section{REFERENCE}

[1] Wen-Jie Ge. Deepening the Teaching Reform and Construction with 'Quality and Innovation' as the Core $[\mathrm{J}]$.Chinese University Teaching,2013(7).

[2] Bing-Lin Zhong. Promote Science and Education Integration in University, and Strive to Cultivate Innovative Talents[J]. Chinese University Teaching,2012(5). 
[3] Tang Zhixiang. Jiang Zemin's Educational Innovation Studies [M]. Changsha; Hunan People's Publishing House, 2003.

[4] Zhu Qingshi. Reform and Development of Higher Education in the 21st Century [M]. Beijing: Higher Education Press, 2002.

[5] Li Wuyi, Xing Yongfu. Frontier Research in China Education [M]. Taiyua: Shanxi Education Press, 2004.

[6] Ministry of Education. Observations with Regard to Further Deepening the Reform of Undergraduate Education, and Comprehensively Improve the Quality of Education[R].2\#[2007] Higher eduction of the Ministry of eduction.

[7] Information and Computing Science Department Working Group on Reform of the Teaching in Xiamen University Tan Kah Kee College. Xiamen University Tan Kah Kee College Information and Computer Science Training Program 2008.

[8] Zou Xiaodong. Innovation in Science and Engineering Education: Strategies, Patterns and Countermeasures [M]. Beijing Science Press, 2010 .
[9] Meng Xianzhi. A Research of Disciplinary Theory and Practice on Construction of New Private College [M]. Beijing: Chinese Academy of Agricultural Science and Technology Press, 2009.

[10] Zhang Zhonghua. Modern Teaching Methodology [M]. Harbin: Heilongjiang People's Publishing House, 2009.

[11] Gao Youhua. A Study on Theory of New Higher Education Courses [M] Zhenjiang: Jiangsu University Press, 2009.

[12] Ping-Xiang Wang and Tie-Jun Tang. Exploration of Building Personnel Training Mode Innovation Experimental Areas[J]. Chinese University Teaching,2010(5)

[13] Ting-Qi Ma. New Progress of the Mode Reformation of Talents Training in Chinese Research University[J]. Higher Educational Research,2009(4)

[14] Xiao-Ming He. Cultivation of College and University Students' Innovation Ability[J]. Teaching Research,2002(1). 